\title{
Analisis Pengaruh Kampanye Public Relations \#SaveGBK dan Identitas Sosial Pada Sikap Jakmania Depok
}

\author{
Retor Aquinaldo Wirabuanaputera Kaligis ${ }^{1}$, Aprilianti Pratiwi², \\ Faridhian Anshari ${ }^{3}$ \\ 1,2,3Fakultas Ilmu Komunikasi, Universitas Pancasila \\ Jl. Srengseng Sawah, Jagakarsa, Jakarta Selatan 12640 Indonesia \\ Email: retorawkaligis@univpancasila.ac.id ${ }^{1 *}$; aprilyantipratiwi@univpancasila.ac.id²; \\ faridhian@univpancasila.ac.id ${ }^{3}$ \\ *Corresponding author
}

\begin{abstract}
Persija Jakarta repeatedly received sanctions from PSSI in the form of a ban on playing at the Stadion Utama Gelora Bung Karno (SUGBK) because of the actions of its supporters, The Jakmania. The Jakmania conducted a public relations campaign \#SaveGBK to bring order to its members and improve its image. This study aims to analyze the influences of the \#SaveGBK campaign and social identity on Jakmania members'attitude. The theory used is Image Restoration Theory. This research uses the convergent parallel mix-method, the data collection techniques were carried out by distributing questionnaires to The Jakmania members and conducting interviews to the head of supporters who's involved in the campaign. The survey population were members of The Jakmania Depok who, although not living in Jakarta, supported Persija as a Jakarta soccer club and participated in the campaign. This research concludes that there is a linkage of the \#SaveGBK campaign with the attitude of The Jakmania. This proves that the improvement program from within the organization and leadership that is able to manage the communication network can discipline its members. Although the majority of respondents have parents from the Betawi ethnicity, ethnic social identity has no effect on respondents' attitudes. The substance of this research is in the form of policy proposals on The Jakmania in order to build an approach strategy with the media through a special team of media relations to improve the image and promotion of the organization.
\end{abstract} Keywords: Public Relations Campaign; SaveGBK; Social Identity; The Jakmania

\begin{abstract}
Abstrak
Persija Jakarta berulangkali mendapat sanksi dari PSSI berupa larangan bermain di Stadion Utama Gelora Bung Karno(SUGBK) karena ulah suporternya, The Jakmania. The Jakmania melancarkan kampanye public relations \#SaveGBK untuk menertibkan anggota dan memperbaiki citra. Penelitian ini bertujuan menganalisis pengaruh kampanye \#SaveGBK dan identitas sosial pada sikap anggota Jakmania. Teori yang digunakan adalah Image Restoration Theory. Penelitian ini menggunakan metode campuran paralel konvergen, teknik pengumpulan data dilakukan dengan menyebarkan kuesioner kepada anggota Jakmania dan melakukan wawancara dengan pimpinan suporter yang terlibat dalam kampanye. Populasi survei adalah anggota The Jakmania Depok, yang walaupun tidak tinggal di Jakarta, mendukung Persija sebagai klub sepak bola Jakarta dan berpartisipasi dalam kampanye. Penelitian ini menyimpulkan adanya keterkaitan kampanye public relations \#Save GBK dengan sikap The Jakmania. Hal tersebut membuktikan bahwa program perbaikan dari dalam organisasi dan kepemimpinan yang mampu mengelola jaringan komunikasi dapat menertibkan para anggotanya. Meski mayoritas responden memiliki orang tua berasal dari suku Betawi, identitas sosial kesukuan tidak berpengaruh terhadap sikap responden. Substansi penelitian ini berupa usulan kebijakan pada The Jakmania agar membangun strategi pendekatan dengan media melalui tim khusus media relations guna memperbaiki citra dan promosi organisasi. Kata kunci: Kampanye Public Relations; SaveGBK; Identitas Sosial; The Jakmania
\end{abstract}

\section{Pendahuluan}

Suporter klub sepakbola di Indonesia memperoleh citra negatif dari sebagian masyarakat karena diidentikkan sebagai pembuat onar. Citra itu juga melekat pada The Jakmania. Berulang kali Persija dilarang bermain di Stadion Utama Gelora Bung Karno (SUGBK) akibat ulah suporternya. Pada 24 Juni 2016 kerusuhan terjadi pada laga Persija Jakarta kontra Sriwijaya FC di Stadion Utama Gelora Bung Karno (SUGBK). Para anggota The Jakmania membuat ulah dengan melakukan 
pelemparan benda-benda keras ke aparat, serta perusakan dan pembakaran kendaraan pribadi dan aparat. Komisi Disiplin ISC (Indonesia Soccer Championship) memberikan sanksi kepada Persija Rp 150 juta dan The Jakmania tidak boleh menghadiri pertandingan Persija selama 6 bulan (Prasetya, M.H. Tribunnews.com, 2016).

Keberadaan SUGBK menjadi penting bagi Persija dan The Jakmania karena Persija sedang tidak memiliki stadion kandang (homebase) yang permanen setelah Stadion Menteng dirobohkan jadi taman kota pada 2006 dan Stadion Lebak Bulus dihancurkan untuk dibangun terminal MRT (Mass Rapid Transit) pada 2015. SUGBK menjadi satu-satunya stadion sepakbola di Jakarta yang layak untuk pertandingan kompetisi berskala nasional.

Pasca peristiwa 24 Juni 2016 The Jakmania dan Persija berbenah diri. Ketua umum The Jakmania diganti oleh Ferry Indrasjarief yang terpilih melalui Musyawarah Luar Biasa The Jakmania di Jakarta, 22 Januari 2017. Ferry merupakan salah satu The Jakmania dan pernah menjadi ketua umum pada 1999-2005. Selama periode kepemimpinannya (2017-2020), Ferry berjanji lebih menertibkan The Jakmania (Ferry Indrasjarief, 6 November 2018).

Pihak Persija juga mengampanyekan \#SaveGBK untuk mengajak pendukungnya tidak membuat kerusuhan, terutama saat menjadi tuan rumah di SUGBK. Kampanye gerakan ini didukung oleh The Jakmania dalam proses pengoordinasikan suporter dari tingkat pengurus pusat hingga anggota, baik untuk mendukung di lapangan maupun di media sosial, seperti Instagram, yang memunculkan varian slogan, yakni \#JagaGBK. Intinya, gerakan tersebut merupakan kampanye public relations karena ke dalam organisasi bertujuan membuat anggota The Jakmania berperilaku lebih tertib, adapun ke luar bertujuan memperbaiki citra suporter tersebut di mata masyarakat. SUGBK dijadikan objek gerakan karena stadion itu homebase satu-satunya di ibukota yang harus dijaga.
The Jakmania kembali menjadi perhatian publik pada final Piala Presiden antara PersijaBali United pada 17 Februari 2018. Saat itu pagar pembatas dan kursi penonton di salah satu sektor stadion dirusak oleh oknum The Jakmania. Skala kejadian itu tidak besar tetapi publik memberi sorotan negatif karena stadion itu baru pertama kali digunakan pasca renovasi untuk persiapan Asian Games 2018 yang tinggal 6 bulan lagi (Agustus 2018).

Konsolidasi dan menertibkan organisasi, The Jakmania memiliki mekanisme pertemuan langsung dan pemanfaatan media sosial. Ketua umum The Jakmania Ferry Indrasjarief mengatakan: "Secara berkala Pengurus Pusat The Jakmania menyelenggarakan briefing dengan para Korwil. Masing-masing Korwil punya Whatsapp Group untuk ke Sub Korwil dan anggota, bagian Infokom itu punya Instagram" (Ferry Indrasjarief, 6 November 2018).

The Jakmania memiliki struktur organisasi dari pengurus pusat yang membawahi para Kordinator Wilayah (Korwil), kemudian Korwil-Korwil tersebut mengelola anggotanya. Per November 2018 The Jakmania memiliki 66 Korwil dengan 45 ribu anggota. Korwil tidak hanya berada di DKI Jakarta, tetapi juga di Depok, Tangerang, Bogor, Bekasi, hingga Tegal. Basis pendukung di Jabodetabek yang dihuni oleh beragam suku, Ferry menjelaskan: "The Jakmania dibangun dengan identitas anggotanya sebagai "anak Jakarta" yang dibedakan dengan suku Betawi" (Ferry Indrasjarief, 6 November 2018). Banyak anggota The Jakmania berdomisili di sekitar ibukota dan di luar Persija yang belum mampu bersaing di kompetisi nasional, sehingga tidak dapat menjadi kebanggaan warga, seperti Persikabo Bogor dan Persikad Depok.

Penelitian Hadi (2017: 131-151) menjelaskan Bobotoh pendukung Persib memberikan ruang bagi terciptanya identitas yang merujuk pada lokalitas (Bandung) sekaligus etnisitas (kesundaan). Pemanfaatan komunikasi digital, Bobotoh Persib menghasilkan kontruksi iden- 
titas yang merepresentasikan penduduk Sunda asli dan pendatang yang terhubung dengan masyarakat global. Penelitian Doewes \& Riyadi (2016: 718-725) menunjukkan bahwa status sosial-ekonomi Aremania bercampur identitas lokalitas. Identitas Aremania dibangun berdasarkan karakter "kejawatimuran" yang keras dan ulet menghadapi situasi apapun, meski kondisi keuangan supporter terbatas, sebagaimana tercermin dari julukan yang melekat pada diri suporter: bonek (bondo atau modal nekad).

Koerber \& Zabara (2017: 193) memaparkan dunia olahraga merupakan bidang yang berkembang dalam penelitian hubungan masyarakat dan komunikasi krisis, yang didominasi studi tentang perbaikan citra atlet dan tim, solidaritas penggemar selama krisis, serta peran massa dan media baru dalam perkembangan krisis. Pelanggan ritel yang memiliki hubungan sederhana dengan toko, penggemar olahraga membeli tiket untuk mendapatkan akses ke drama publik yang menarik drama yang tidak ditemukan pada sebagian besar produk atau layanan lainnya. Penggemar olahraga terlibat setiap hari di komunitas online dan offline. Asumsi dalam studi komunikasi krisis secara umum dan komunikasi krisis olahraga secara khusus, lanjutnya bahwa tanpa komunikasi strategis yang efektif selama tahap respons, krisis menyebabkan kerusakan langsung dan serius pada reputasi dan citra individu dan organisasi yang terlibat.

Penelitian terdahulu tentang suporter Persib dan Arema dibandingkan dengan penelitian ini yaitu memiliki perbedaan menyangkut identitas sosial suporter suatu klub sepakbola yang tidak terikat lokalitas dan mendiami wilayah dengan beragam suku. Hal ini dapat menjadi salah satu dasar membangun fanatisme positif suporter sesuai karakterik majemuk masyarakat Indonesia. Berbeda dengan penelitian Koerber \& Zabara yang meneliti public relations dan komunikasi krisis pada tim dan atlet dalam hubungannya dengannya publik, terma- suk suporter, penelitian ini mengulas public relations dalam kaitannya dengan perbaikan citra organisasi suporter klub sepakbola di masyarakat melalui penertiban internal dengan menggunakan Image Restoration Theory.

\section{Image Restoration Theory}

Kampanye public relations memiliki proses dan teknik komunikasi tertentu. Ruslan (2013, 71-74) menjelaskan, terdapat beberapa teknik kampanye yang digunakan dalam kegiatan public relations, yaitu: 1) Partisipasi (participasing): teknik mengikutsertakan (partisipasi) audiens yang memancing minat atau perhatian yang sama ke dalam suatu kegiatan kampanye dengan tujuan untuk menumbuhkan saling pengertian, menghargai, kerja sama, dan toleransi; 2) Asosiasi (association): menyajikan isi kampanye yang berkaitan dengan suatu peristiwa atau objek yang tengah ramai dibicarakan agar dapat memancing perhatian dan respon masyarakat; 3) Integratif (integrative): upaya menyatukan diri seorang komunikator kepada khalayaknya secara komunikatif dengan mengucapkan kata-kata: "kita, kami, anda sekalian atau untuk Anda, dan sebagainya" yang artinya apa disampaikan pihak komunikator bukan untuk kepentingan dirinya atau kelompoknya, melainkan untuk kepentingan bersama; 4) Ganjaran (pay off technique): teknik ganjaran bermaksud untuk mempengaruhi komunikan dengan suatu ganjaran (pay off) atau menjanjikan sesuatu dengan "imingiming hadiah"; 5) Penataan Patung Es (icing technique): teknik ini merupakan upaya untuk menyampaikan pesan dalam kampanye agar enak dilihat, dibaca, didengar, dan dirasakan seperti menata balok es yang dibentuk sedemikian rupa sehingga menarik; 6) Memperoleh Empati (emphaty): kampanye ini menempatkan diri di posisi komunikan, ikut merasakan dan peduli pada situasi dan kondisi. Praktik public relations biasanya ini disebut dengan social responsibility dan human relations; 7) Koersi atau Paksaan (coercion technique): melakukan kampanye 
dengan unsur paksaan dan menekankan sehingga menimbulkan rasa kekhawatiran jika tidak tunduk melalui ancaman tertentu.

Kampanye public relations gerakan \#Save GBK ke dalam organisasi berusaha membuat anggota The Jakmania berperilaku lebih tertib, adapun ke luar bertujuan memperbaiki citra suporter tersebut di mata masyarakat. Benoit (1997:178-9), penggagas Image Restoration Theory (IRT) mengatakan, strategi perbaikan citra mempertimbangkan sifat serangan atau keluhan yang mendorong respons semacam itu atau memicu krisis. Serangan memiliki dua komponen: pihak tertuduh bertanggung jawab atas suatu tindakan dan tindakan itu dianggap ofensif. Bennoit menilai persepsi dari khalayak terkait lebih penting daripada kenyataan. Bennoit lalu mengemukakan lima strategi memperbaiki citra, yakni denial (menyangkal kesalahan), evasion of responsibility (upaya menghindari tanggung jawab terhadap persoalan yang ada), reduce the offensiveness of act (mengurangi serangan), corrective action (tindakan korektif mengatasi masalah dan mencegah agar tidak terulang lagi), dan mortification (mencoba memulihkan citra dan meminta maaf).

Penggunaan IRT bukan hal baru dalam dunia olah raga. Ibrahim (2017: 1-18) meneliti strategi perbaikan citra pada FIFA (Fédération Internationale de Football Association) setelah sejumlah pejabatnya ditangkap karena kasus korupsi sehubungan tawaran untuk Piala Dunia 2018 dan 2022. Ibrahim menemukan bahwa FIFA bergantung pada strategi denial untuk menghindari tanggung jawab. FIFA menyelenggarakan konferensi pers untuk membuat beberapa pernyataan melalui situs web resmi, dengan sedikit penggunaan media. Citra FIFA yang memburuk membuat Ibrahim menilai bahwa reputasi asosiasi sepakbola internasional di masa depan tergantung pada kemampuan berkonsentrasi pada penggunaan media, terutama untuk meningkatkan kesadaran masyarakat internasional tentang perannya di bidang olahraga.
Coombs \& Holladay (2008:252-7) mengingatkan agar pihak yang bermasalah tidak hanya mengandalkan mortifikasi sebagai obat mujarab untuk pemulihan citra. Coombs \& Holladay menyarankan pemilihan strategi berdasarkan sifat dan besarnya krisis. Strategi mortifikasi (mortification) perlu dibarengi tindakan korektif (corrective action) agar menjadi strategi yang efektif menghentikan penyebaran krisis dan memulihkan citra.

Kampanye public relations \#SaveGBK dapat ditelaah sebagai strategi memperbaiki citra The Jakmania. Mengacu pada Rice et al. (2017: 110), komunikasi, kolaborasi, dan proses informasi yang didukung teknologi baru informasi dan komunikasi dalam organisasi menjembatani batas geospasial dan temporal yang menjangkau tiga tingkat organisasi, yang antarpribadi, kelompok, dan organisasi. Pada tingkat interpersonal anggota organisasi sering terlibat dalam komunikasi diadik dan tingkat kelompok dapat berhubungan dengan kelompok kerja atau tim, maka pada tingkat organisasi berpotensi signifikan terhadap proses komunikasi organisasi yang terpusat, seperti sosialisasi, berbagi pengetahuan, dan hubungan kekuasaan.

\section{Teori Identitas Sosial}

Manusia biasa hidup di berbagai lingkungan sosial dan memiliki sejumlah identitas sosial. Identitas sosial merupakan produk dari perilaku komunikatif karena dibentuk dan dikembangkan melalui interaksi sosial, memeriksa interaksi individu dan hubungan dengan orang lain atau afiliasinya dengan kelompok sosial tertentu (Guan \& So, 2016: 589-90). Komunikasi memainkan peran penting dalam menyampaikan informasi secara langsung atau tidak langsung tentang identitas sosial tentang kelompok, diri sendiri (Hogg, 2018: 111). Produk perilaku komunikatif manusia lebih menonjolkan identitas sosial tertentu dalam menjalankan aktivitas sehari-harinya sekaligus menyalurkan eksistensi diri. 
Feitosa et al. (2012: 529-31) mengidentifikasi tiga dimensi identitas sosial, yaitu kategorisasi (categorization), rasa memiliki (sense of belonging), dan sikap positif (positive attitudes). Kategorisasi mencakup penilaian diri sebagai anggota kelompok yang menjadi cerminan baik tentang diri, melihat orang dari luar kelompok sebagai berbeda, dan menganggap keberhasilan kelompok merupakan kesuksesan diri. Rasa memiliki mencakup keterlibatan dalam kelompok, menganggap kritikan terhadap kelompoknya sebagai kritikan terhadap pribadi, dan kecocokan hubungan dengan kelompok secara keseluruhan. Adapun sikap positif mencakup rasa senang, bangga, dan baik menjadi anggota kelompok, menyukai banyak orang di kelompok.

\section{Teori Sikap}

Teori tripartit (the tripartite theory) dari Rosenberg \& Hovland menjelaskan ada tiga jenis respons yang mungkin terhadap stimulus: afeksi, kognisi, dan perilaku di mana afeksi digunakan untuk menggambarkan perasaan positif dan negatif yang dimiliki seseorang terhadap objek sikap (Albarracin, Johnson, \& Zanna, 2005: 82). Azwar (2016: 24-28) menjelaskan struktur sikap berdasarkan tiga komponen: Pertama, komponen kognitif merupakan representasi apa yang dipercayai seseorang atau pemilik sikap. Komponen ini adalah kepercayaan yang dimiliki seseorang mengenai suatu (opini) tentang yang menyangkut isu atau masalah yang kontroversial. Kedua, komponen afektif menyangkut perasaan dan aspek emosional seseorang terhadap sesuatu. Aspek ini adalah salah satu bagian dari komponen sikap yang paling dalam dan paling bertahan terhadap pengaruh yang mungkin mengubah sikap seseorang. Ketiga, komponen konatif sebagai aspek kecenderungan sikap yang dimiliki seseorang untuk bertindak atau bereaksi terhadap sesuatu dengan cara - cara tertentu berkaitan dengan objeknya.
Sikap menjadi penentu tingkah laku manusia terhadap kondisi atau situasi lingkungan sekitarnya. Gokodall (2011: 3) menyatakan:

"The use of implicit measures of attitudes has great potential to advance our understanding of process and mechanism in the field of communication. These measures assess automatically activated attitudes, which have the potential to influence spontaneous decisions and outcomes, and may operate, to some extent, below individuals " consciousness". Porat (2010: 287-8) mengatakan bahwa anggota komunitas suporter (fandom) sepakbola memiliki ketegangan pada kepribadiannya. Suporter adalah anggota keluarga, karyawan, teman, dan lainnya tapi menganggap lebih tinggi dan lebih penting klub sepakbolanya dan menjadi penggemar daripada peran sosial lainnya. Dari ketegangan itu, kesetiaannya yang konkrit kepada klub diuji dan diukur.

Berdasar latar belakang yang dipaparkan, tujuan penelitian ini untuk menganalisis pengaruh kampanye public relations \#Save GBK dan identitas sosial pada sikap The Jakmania Kota Depok, yang walaupun tidak tinggal di Jakarta tetapi mendukung Persija sebagai klub sepakbola ibukota.

\section{Metode Penelitian}

Penelitian ini menggunakan metode campuran paralel konvergen (the convergent parallel mix-method) di mana peneliti mengumpulkan data kuantitatif dan kualitatif, menganalisisnya secara terpisah, kemudian hasilnya dibandingkan untuk melihat sejauhmana temuan-temuan kuantitatif dan kualitatif saling mengonfirmasi. Pengumpulan data kuantitatif dan kualitatif secara sekuensial dalam satu studi mempertemukan dua jenis informasi yang memberikan pemahaman dan wawasan yang lebih luas ke dalam topik penelitian yang mungkin belum bisa diperoleh dengan menganalisis dan mengevaluasi data secara terpisah (Bowen, Rose, \& Pilkington, 2017:10). Pendekatan metode campuran, penelitian 
yang dilakukan dapat menarik kekuatan dan meminimalkan kelemahan dari masing-masing pendekatan. Pengolahan kuesioner menggunakan statistik inferensial dalam penelitian kuantitatif dimaksudkan untuk mengukur hasil objektif realitas. Wawasan mendalam tentang suatu fenomena, yang menjadi kekuatan penelitian kualitatif, dapat diperoleh dari informan kunci. Huiberts (2016: 4339) menjelaskan bahwa pendekatan metode campuran juga memberikan kontribusi bagi penelitian di masa depan untuk mengintegrasikan pengetahuan masa lalu dan masa depan serta mengklarifikasi banyak hal, baik pada tingkat generalisasi melalui studi kuantitatif dan kedalaman dengan studi kualitatif.

Penelitian kuantitatif, Variabel Bebas (X1): Teknik Kampanye Public Relations merupakan cara-cara yang terorganisir oleh Persija Jakarta dan organisasi The Jakmania Jakarta menggerakkan para anggota The Jakmania agar mengubah pola pikir, memotivasi atau membujuk sehingga dapat memperbaiki citra.

Identitas sosial dilihat apakah sebagai produk dari perilaku komunikatif faktor latar belakang kesukuan menjadi dasar seseorang menjalankan aktivitas dan menyalurkan eksistensi diri di The Jakmania. Pada penelitian kuantitatif, Variabel X2: Keturunan Betawi dari Pihak Ayah dan X3: Keturunan Betawi dari Pihak Ibu yang keduanya dijadikan dummy variable. Pada Variabel Terikat (Y): Sikap merupakan kecenderungan untuk berpersepsi, berpikir, merasa, dan bertindak para anggota komunitas dalam kampanye public relations \#SaveGBK, baik bersifat tidak mendukung, pasif mendukung, maupun aktif mendukung.

Teknik pengumpulan data kuantitatif menggunakan survei pada The Jakmania Kota Depok dengan instrumen kuesioner tertutup. Populasi penelitian ini adalah para anggota The Jakmania Kota Depok yang berdasarkan data resmi per akhir November 2018 berjumlah 1674 orang. Mengenai besar sampel tidak ada ukuran pasti, tapi bila populasi cukup banyak pecahan sampling minimal 10\% sudah dianggap memadai (Kriyantono, 2014). Penggunaan teknik penarikan sampling kebetulan (accidental sampling), penyebaran kuesioner dilakukan di tempat-tempat para anggota The Jakmania Kota Depok berkumpul (kopi darat) di Depok dan sekitarnya selama 2 bulan (OktoberNovember 2018). Sampel yang diperoleh 256 responden anggota The Jakmania Kota Depok. Unit analisisnya adalah individu. Skala Likert digunakan untuk mengukur persepsi tentang kampanye public relations gerakan \#SaveGBK dan sikap responden. Nilai yang digunakan Sangat Tidak Setuju (1); Tidak Setuju (2); Netral (3); Setuju (4), dan Sangat Setuju (5).

Pada teknik penelitian data kualitatif digunakan wawancara semi terstruktur dengan informan kunci penelitian Ferry Indrasjarief, salah satu pendiri dan Ketua Umum The Jakmania 2017-2020 (wawancara 6 November 2018), Larico Ranggamone, mantan Ketua Umum The Jakmania 2012-2016 (wawancara 26 Oktober 2018), dan Dwi Rio Sambodo, salah satu penasihat The Jakmania yang juga anggota Komisi E DPRD DKI Jakarta (wawancara 31 Oktober 2018). Peneliti sebagai instrumen melakukan wawancara langsung untuk menggali data dan menginterpretasikannya.

Analisis data kuantitatif diambil dari hasil olahan kuesioner. Kriteria penilaian deskriptif kuantitatif menggunakan metode rating scale. Analisis Regresi Linear Berganda digunakan untuk melihat pengaruh kampanye public relations gerakan \#SaveGBK dan identitas sosial terhadap sikap The Jakmania Kota Depok. Secara terpisah peneliti juga menggunakan hasil wawancara untuk dianalisa. Hasil temuan kuantitatif dan kualitatif dibandingkan untuk melihat sejauhmana saling mengonfirmasi dan dilakukan penarikan kesimpulan.

Uji validitas item digunakan di mana dengan jumlah responden $(n)=256$, maka $\mathrm{df}=(\mathrm{N}-2)=256-2=254$. Dengan $\mathrm{df}=254$ dan $\alpha=0.05, \mathrm{r}$ tabel adalah 0,123 . Dari hasil 
perhitungan validitas data variabel Teknik Kampanye diperoleh hasil seluruh item yang digunakan (X-1 hingga X-31) valid karena seluruh nilai $r$ hitung berada diatas $r$ tabel, yakni berada pada rentang 0,427-0,766. Adapun dari hasil perhitungan validitas data variabel Sikap diperoleh hasil seluruh item (Y-1 hingga Y-15) juga valid karena seluruh nilai $r$ hitung berada diatas $\mathrm{r}$ tabel, yakni berada dalam rentang 0,507-0,756. Hasil perhitungan uji reliabilitas diperoleh hasil Teknik Kampanye: 0,952, dan Sikap: 0,887 . Semua variabel dinyatakan reliabel karena memiliki alpha $>0,7$, artinya semua variabel dalam kuesioner memiliki konsistensi atau dapat diandalkan. Adapun dalam penelitian kualitatif dilakukan triangulasi sumber untuk membandingkan narasumber satu denganlainnya.

\section{Hasil Penelitian dan Pembahasan Temuan Data Kuantatif Profil Responden}

Responden dalam penelitian ini merupakan 256 anggota Jakmania Kota Depok, pria mendominasi sebesar $92,2 \%$ sementara wanita $7,8 \%$. Dari segi usia, rentang terbanyak berusia 20 tahun atau kurang (34,0\%). Semakin tua usia responden, jumlah respondennya semakin sedikit, yakni berturut-turut 21-25 tahun (26,65\%), 26-30 tahun (18,0\%), 31-35 tahun (12,1\%), 36-40 tahun $(6,6 \%)$, dan 41 tahun atau lebih $(2,7 \%)$. Segi pendidikan, mayoritas responden berpendidikan SLTA $(59,4 \%)$, sementara itu terdapat $14,1 \%$ berpendidikan SLTP, $11,7 \%$ berpendidikan D3 atau sedang kuliah, dan 9,8\% sarjana. Selebihnya $2,7 \%$ berpendidikan pascasarjana dan 2,3\% berpendidikan SD. Sejalan dengan karakteristik responden yang didominasi usia muda, pekerjaan atau status responden terbanyak adalah pelajar atau mahasiswa $(32,8 \%)$. Karyawan swasta menempati urutan kedua (28,9\%), kemudian tidak bekerja atau sedang mencari kerja $(19,1 \%)$, berwiraswasta $(12,9 \%)$, dan terakhir PNS atau Pegawai BUMN (6,3\%).
Sebagian besar responden menjadi anggota Jakmania 5 tahun atau kurang, terdiri responden yang jadi anggota selama 2-5 tahun $(39,5 \%)$ dan 1 tahun atau kurang (36,3\%). Responden yang menjadi anggota selama 6-10 tahun $(10,2 \%), 11$ 15 tahun $(5,1 \%), 16-20$ tahun $(4,3 \%)$, dan terakhir 21 tahun atau sejak Jakmania berdiri (4,7\%). Segi lama menetap, responden yang tinggal di Depok 21 tahun atau lebih menempati urutan terbanyak (25\%), kemudian tinggal di Depok $2-5$ tahun $(20,7 \%), 1$ tahun atau kurang $(19,1 \%)$, 16-20 tahun (15,2\%), 6-10 tahun (11,7\%), dan 11-15 tahun (8,2\%). Karakteristik responden yang sebagian besar berusia muda, maka mayoritas responden sejak lahir atau setidaknya sejak kecil tinggal di Depok. Jumlah responden yang pernah tinggal di Jakarta 52,7\%, adapun sebanyak 47,3\% tidak pernah tinggal di Jakarta. Jumlah dan persentase ini menunjukkan antara responden yang pernah dan tidak pernah tinggal di Jakarta cenderung berimbang, artinya menjadi anggota The Jakmania tidak ditentukan oleh latar belakangnya pernah tinggal di Jakarta atau tidak.

Mayoritas responden memiliki darah Betawi dari pihak ayah $(67,6 \%)$, sisanya $32,4 \%$ tidak ada darah Betawi dari pihak ayah. Mayoritas responden juga memiliki darah Betawi dari pihak ibu $(62,9 \%)$ dibandingkan $37,1 \%$ tidak punya darah Betawi dari pihak ibu. Mayoritas responden memiliki salah satu atau kedua orang tua berasal dari suku Betawi sehingga penting diketahui sejauhmana identitas kesukuan memengaruhi sikap sebagai anggota The Jakmania.

Tabel 1. Kriteria Penilaian Variabel Teknik Kampanye

\begin{tabular}{ccl}
\hline No & Range & \multicolumn{1}{c}{ Penafsiran } \\
\hline 1 & $31-55$ & Sangat Rendah \\
2 & $56-80$ & Rendah \\
3 & $81-105$ & Sedang \\
4 & $106-130$ & Tinggi \\
5 & $131-155$ & Sangat Tinggi \\
\hline
\end{tabular}

Sumber: Olahan penelitian (2019) 
Tabel 2 Statistik Deskriptif Teknik Kampanye

\begin{tabular}{lrrrc}
\hline & N & Minimum & Maximum & Mean \\
\hline Total_Teknik_Kampanye & 256 & 60 & 155 & 124,37 \\
Valid N (listwise) & 256 & & & \\
\hline
\end{tabular}

Sumber: Olahan penelitian (2019)

\section{Deskripsi Variabel Teknik Kampanye}

Pada variabel Teknik Kampanye, lima (5) sebagai nilai tertinggi per butir jawaban kuesioner dan 31 jumlah pertanyaan, maka jumlah skor kriterium tertinggi $=5 \times 31=155$. Nilai terendah 1 dan 31 jumlah pertanyaan, maka jumlah skor kriterium terendah $=31$. Dengan demikian jarak antara interval Teknik Kampanye adalah: (155-31):5 = 24,8, dibulatkan menjadi 25, yang dijabarkan pada tabel 1 .

Hasil perhitungan SPSS menunjukkan, nilai minimum dan maksimum jawaban responden 60 dan 155. Adapun skor ratarata jawaban responden pada variabel Teknik Kampanye adalah sebesar 124,37 (tabel 2), artinya, rata-rata Teknik Kampanye yang dilakukan menurut responden adalah tinggi.

\section{Deskripsi Variabel Sikap}

Variabel Sikap di sini menyangkut segi kognisi, afeksi, dan konasi. Pada variabel ini, dengan 5 sebagai nilai tertinggi per butir jawaban kuesioner dan 15 jumlah pertanyaan, maka jumlah skor kriterium tertinggi $=5 \times 15=75$. Adapun dengan nilai terendah 1 dan 15 jumlah pertanyaan, maka jumlah skor kriterium terendah $=15$. Dengan demikian jarak antara interval adalah: (75-15):5 = 12, yang dijabarkan dalam tabel 3 .

Hasil perhitungan SPSS menunjukkan, nilai minimum dan maksimum jawaban responden 33 dan 75. Adapun skor rata-rata jawaban responden pada variabel Sikap adalah sebesar 60,89 (tabel4). Artinya, rata-rata Sikap responden adalah tinggi.

\section{Uji Regresi Berganda}

Regresi berganda digunakan untuk menjawab sejauhmana pengaruh teknik kampanye dan identitas sosial terhadap sikap Jakmania.
Tabel 5 diketahui nilai $\mathrm{t}$ hitung adalah 27,028, responden 256 maka df adalah 256-2= 254 , jadi t tabel untuk 0,05 adalah $=1,969$. Hal ini berarti nilai t hitung lebih besar daripada nilai $t$ tabel, maka terdapat pengaruh signifikan teknik kampanye terhadap sikap The Jakmania. Darah Betawi dari pihak ayah memiliki koefisien regresi -0,199 atau menurunkan Sikap The Jakmania sebesar 1,99\% dan darah Betawi dari pihak ibu memiliki koefisien regresi $-0,66 \%$ atau menurunkan Sikap The Jakmania sebesar $0,66 \%$. Dari t hitung yang lebih kecil t tabel (darah Betawi dari pihak ayah -0,389 dan darah Betawi dari pihak ibu -1,339) menunjukkan bahwa tidak terdapat pengaruh signifikan darah Betawi dari pihak ayah dan ibu terhadap sikap, malah cenderung sedikit melemahkan. Mayoritas responden memiliki salah satu atau kedua orang tua berasal dari suku Betawi tapi identitas sosial suku tidak berpengaruh terhadap sikap responden. Hasil pengujian koefisien determinasi diketahui R Square $=0,744$ (tabel 6), yang berarti teknik kampanye memengaruhi sikap The Jakmania sebesar $74,4 \%$ atau kuat.

\section{Temuan Data Kualitatif}

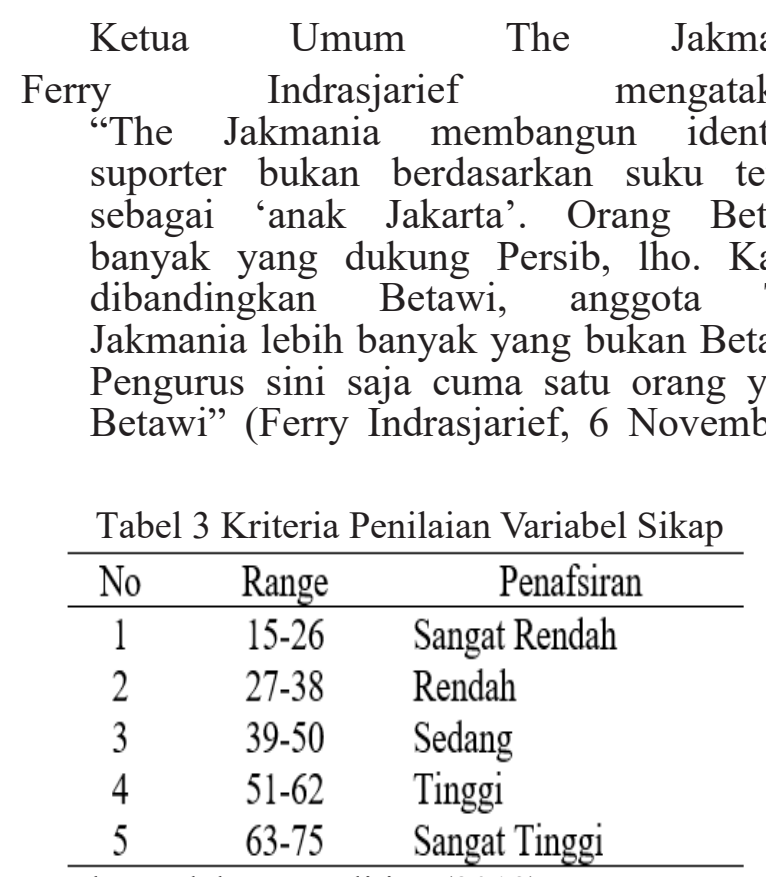

Sumber: Olahan penelitian (2019) 
Tabel 4 Statistik Deskriptif Sikap

\begin{tabular}{lrrrr}
\hline & N & Minimum & Maximum & Mean \\
\hline Total_Sikap & 256 & 33 & 75 & 60,89 \\
Valid N (listwise) & 256 & & &
\end{tabular}

Sumber: Olahan penelitian (2019)

Karakteristik Jabodetabek yang majemuk membuat para pendukung Persija berasal dari berbagai suku. Mereka membangun identitas berdasarkan ciri khas Jakarta sebagai ibukota tanpa bersandar pada suku tertentu. Hal tersebut dikuatkan dengan pendapat Dwi Rio Sambodo, penasihat The Jakmania: "Sejak awal berdiri The Jakmania muncul semacam semboyan 'bukan anak Betawi tapi anak Jakarta', artinya 'anak Jakarta' itu sudah meliputi semua latar belakang dan aspek. Rata-rata anggota The Jakmania berasal dari kalangan menengah ke bawah sehingga menjadikan kegiatan menonton sebagai penyaluran persoalan di rumah, masalah di sekolah, hingga himpitan ekonomi. Mereka ada yang menjadi joki 3 in 1 dan pengamen mencari uang untuk menonton Persija. Kalangan semacam ini tidak bisa mengakses tempat-tempat berkumpul anakanak muda kelas atas Jakarta, sehingga pencarian identitas sebagai 'anak Jakarta' disalurkan melalui The Jakmania."

(Dwi Rio Sambodo, 31 Oktober 2018)

Bagi anak muda Jakarta dan sekitarnya, identifikasi diri sebagai "anak metropolitan" memiliki kebanggaan tersendiri. Dukungan terhadap klub sepakbola ibukota dan kegiatan menonton menjadi katarsis dan saluran pembentukan identitas sosial.
Dwi Rio menguraikan: "Apa sih yang mereka banggakan sebagai anak Jakarta? Kalau orang-orang kaya Jakarta bergaya metropolis, hidup modis, mereka gak bisa. Dengan menjadi anggota The Jakmania mereka mencari kebanggaan sebagai 'anak Jakarta." (Dwi Rio Sambodo, 31 Oktober 2018)

Gerakan \#SaveGBK atau \#JagaGBK sebagai corrective action muncul di kalangan Persija dan The Jakmania, tidak terlepas dari keberadaan klub sepakbola ini yang tidak memiliki stadion kandang (home base) yang permanen di ibukota. Pemain sepak bola yang tidak dapat bermain di SUGBK, maka Persija harus bermain di luar Jakarta yang menyulitkan klub dan suporter.

Larico Ranggamone, mantan Ketua Umum The Jakmania, mengatakan: "Lahirnya gerakan ini bersifat spontan. Ide awalnya dari kita para pengurus sama-sama. Saat itu bermunculan jargon 'Save Persija, 'JagaGBK, dan 'SaveGBK'. Puncaknya tuh setelah bulan puasa 2016 waktu itu Jakmania terusir, Persija gak boleh main lagi di GBK dengan alasan hukuman. Setelah itu ada renovasi GBK. Diminta untuk dijaga jangan sampai terjadi apa-apa. Saya bikin \#SaveGBK iseng-iseng. Sampai ramai semua pakai hashtag \#SaveGBK." (Larico Ranggamone, 26 Oktober 2018)

Larico menambahkan: "Gerakan semacam ini mampu mengajak The Jakmania menjaga SUGBK dan berperilaku lebih tertib karena ada hukuman dari organisasi bagi yang melanggar. Kalau dia dihukum sama orang luar Jakmania mungkin masih berani, karena

Tabel 5 Uji Regresi Berganda Pengaruh Teknik Kampanye dan Identitas Sosial Terhadap Sikap Jakmania

\begin{tabular}{|c|c|c|c|c|c|c|}
\hline \multicolumn{7}{|c|}{ Coefficients $^{a}$} \\
\hline & \multirow[t]{2}{*}{ Model } & \multicolumn{2}{|c|}{$\begin{array}{l}\text { Unstandardized } \\
\text { Coefficients }\end{array}$} & \multirow{2}{*}{$\begin{array}{c}\text { Standardized } \\
\text { Coefficients } \\
\text { Beta } \\
\end{array}$} & \multirow[t]{2}{*}{$\mathrm{t}$} & \multirow[t]{2}{*}{ Sig. } \\
\hline & & $\mathrm{B}$ & Std. Error & & & \\
\hline \multirow[t]{4}{*}{1} & (Constant) & 12,007 & 1,843 & & 6,514 & ,000 \\
\hline & Total Teknik Kampanye & ,397 &, 015 &, 864 & 27,028 & 000 \\
\hline & Darah Betawi dari Ayah &,- 199 &, 513 &,- 014 &,- 389 & ,698 \\
\hline & Darah Betawi dari Ibu &,- 660 & ,493 &,- 048 & $-1,339$ &, 182 \\
\hline
\end{tabular}

Sumber: Olahan penelitian (2019) 
Tabel 6 Koefisien Determinasi Model Summary

\begin{tabular}{rrrrrrr}
\hline Model & $\begin{array}{c}\text { R Square } \\
\text { Change }\end{array}$ & F Change & df1 & df2 & Sig. F Change \\
\hline 1 &, $744^{\mathrm{a}}$ & 736,591 & 1 & 254 &, 000 \\
\hline
\end{tabular}

Predictors: (Constant), Total_Teknik_Kampanye

Sumber: Olahan penelitian (2019)

ini kan sama keluarga sendiri jadi ya pasti takut" (Larico Ranggamone, 26 Oktober 2018)

Pernyataan Larico menunjukkan gerakan penertiban suporter berasal dari dalam organisasi sebagai koreksi diri. Ada pertemuan faktor eksternal sanksi larangan Persija bermain di SUGBK yang berdampak ke suporter dan faktor internal kesadaran diri dari suporter yang membuat gerakan itu dapat tumbuh dan berakar di kalangan The Jakmania. Ferry berpendapat: "Istilah \#JagaGBK berasal dari The Jakmania, tapi kalau \#SaveGBK dari Persija. Kampanye \#JagaGBK untuk lebih menertibkan para anggota The Jakmania setelah SUGBK direnovasi. Zaman Richard (Richard Achmad, Ketua Umum The Jakmania 2016-2017) ada kerusuhan di GBK, ada keributan antara polisi dan Jakmania, jadi diusir, gak boleh main di GBK. Setelah itu GBK dibenerin buat Asian Games. Nah, supaya kita bisa main di sana saya bilang 'Jaga GBK'. Dulu-dulu gak perlu 'Jaga GBK'. Kalau kita mau nonton, kita kasih tahu aturan-aturan dari GBK. Kita tahu polisi nanti mengatur pengamannya kayak gimana, anak-anak jangan ada yang duduk di atas kursi, jangan ada yang merokok di stadion. CCTV ada, jadi kalian pasti ketahuan kalau ada kerusakan. Sekarang hampir semua stadion kursinya 'one man one seat', itu permintaan dari pemerintah. Inggris dulu berhasil mengikis holiganisme dengan cara itu, tidak ada lagi tribun berdiri."

(Ferry Indrasjarief, 6 November 2018)

Kampanye gerakan sekaligus pengumuman kegiatan kepada para anggotanya, The Jakmania memiliki Divisi Infokom (Informasi dan Komunikasi). Instagram digunakan sebagai saluran komunikasinya. Akun resmi Instagram @ infokomjakmania yang mencapai tepat 400 ribu follower per 28 Desember 2018, media sosial ini dapat dikatakan cukup efektif menjangkau para anggota The Jakmania. Menurut Ferry: "Pimpinan The Jakmania memberi ramburambu apa yang musti di-share di media sosial itu. Secara berkala pimpinan The Jakmania mengadakan briefing dengan para Korwil yang kemudian disosialisasi ke Sub Korwil dan para anggota masing-masing." (Ferry Indrasjarief, 6 November 2018). Ferry menambahkan:

"Itu dengan media sosial umumkan 2 hari cukup. Kayak kita pernah ngadain nonton bareng Persija, cukup 2 hari ngumumin, cuma di Instagram, yang datang 10 ribu orang karena sudah terbiasa. Akun resmi kita cuma 1: infokomjakmania. Jadi kalau ada statement 'Bung katanya jadwal diubah?' 'Kata siapa?' 'Kata akun Jakmania12'. Oh itu bukan akun resmi kita" (Ferry Indrasjarief, 6 November 2018) Selain menggunakan Instagram, The Jakmania juga mengandalkan Whatsapp. Ferry memaparkan: "Masing-masing Korwil punya Whatsapp Group. Di bawah Korwil juga punya SubSub Korwil. Kita kalau punya lagu baru, kan bayangan orang gimana ngajarinnya 60 ribu anggota. Gampang, karena sudah terbiasa. Kita punya dirijen, ketika dirijennya kasih tahu, mereka langsung cepat hapal, apalagi kalau dikasih kertas. Demikian juga dengan kampanye apapun, kita sudah terbiasa. Jaringan kita, sudah terbiasa. Jadi ketika ketua bilang begini, nyebar ke Korwil, Korwil ke Sub Korwil, sub Korwil ke anggota itu cepat. Efeknya kalau ada yang melanggar, saya tidak segan-segan menghukum. Kadang-kadang tindakan saya viral, terlalu keras, tapi itu pelajaran buat semua." (Ferry Indrasjarief, 6 November 2018)

Hal tersebut menggambarkan komunikasi organisasi melalui saluran langsung dan media sosial menjadi andalan koordinasi untuk menjalankan kebijakan organisasi, termasuk 
pemberlakuan sanksi. Ferry menjelaskan lebih jauh: "Hukuman yang diberikan bisa berupa pengurangi jatah tiket bagi Korwil yang memiliki anggota bermasalah sebelum si anggota itu datang minta maaf, adapun hukuman yang paling berat adalah pencabutan kartu anggota" (Ferry Indrasjarief, 6 November 2018). Sanksi pencabutan kartu anggota dapat dikatakan efektif menertibkan anggota, karena dengan rata-rata suporter dari kalangan menengah ke bawah hanya mampu membeli tiket kelas ekonomi (kelas 3). Faktanya tiket menonton kelas ekonomi hanya dijual ke anggota dan dikelola Korwil masing-masing.

The Jakmania selalu melakukan corrective action untuk mendisiplinkan anggota saat bergabung, ketika keluar dari The Jakmania maka melakukan mortification (penyesalan dan meminta maaf). Larico Ranggamone menjelaskan: "Waktu kasus perusakan SUGBK pada Piala Presiden 2018, kita meminta maaf ke pihak GBK dan siap memperbaiki" (Larico Ranggamone, 26 Oktober 2018).

Ferry mengakui:

Sebetulnya media juga banyak sekarang memberitakan hal-hal positif. Tapi yang namanya suporter aslinya sebetulnya malas dengan media, malas dekat sama polisi. Sekarang kita jalan bareng, peraturan polisi kita sosialisasikan. Hubungan baik dengan polisi. Tapi bukan berarti kita harus samasama terus. Sama media, gak terlalu spesial, tapi bagus hubungannya Tidak ada strategi khusus pendekatan dengan media dan polisi." (Ferry Indrasjarief, 6 November 2018).

Hal tersebut menunjukkan bahwa gerakan penertiban suporter dari internal belum mengoptimalkan pendekatan eksternal, terutama media. Bentuk kampanye public relations, keberadaan media penting untuk memberikan pemberitaan sisi positif suatu perkembangan organisasi ke masyarakat. Masyarakat masih cenderung melihat berbagai negatif The Jakmania.
Dwi Rio menilai:

"Di dalam diri The Jakmania mengandung energi positif dan negatif. Misalnya dulu ada 'Gerakan Beli Tiket', The Jakmania harus beli tiket karena sebelumnya banyak suporter menorobos ke dalam stadion, itu merupakan gerakan dari internal. Begitu juga kasus perusakan GBK, terdapat perlawanan atau kritik kontruktif terhadap tindakan destruktif tersebut untuk menjadikan The Jakmania lebih baik. Ketika ada teman-temannya yang melakukan tindakan destruktif, mereka akan membuat gerakan sebaliknya."

(Dwi Rio Sambodo, 31 Oktober 2018) Penggunaan metode campuran paralel konvergen membuat temuan data kuantitatif dapat digeneralisasi dan hasil data kualitatif menyediakan informasi tentang konteksnya yang dalam penelitian ini memiliki konvergensinya.

Mengacu pada data kuantitatif, mayoritas responden dalam penelitian ini adalah pria. Usia mayoritas 25 tahun atau kurang, lebih dari dua pertiga pendidikan responden adalah SLTP dan SLTA. Segi pekerjaan, sepertiga responden masih berstatus pelajar atau mahasiswa, urutan kedua ditempati karyawan swasta, dan urutan ketiga adalah tidak bekerja atau sedang mencari pekerjaan. Hal ini berarti, responden rata-rata berusia muda dengan pendidikan yang tidak tinggi dan hidupnya belum mapan. Mayoritas responden memiliki salah satu atau kedua orang tua berasal dari suku Betawi, tetapi sebagian besar responden sejak lahir atau setidaknya sejak kecil tinggal di Depok. Jumlah antara responden yang pernah dan tidak pernah tinggal di Jakarta cenderung berimbang.

Temuan data kualitatif terungkap bahwa rata-rata anggota The Jakmania berasal dari kalangan menengah ke bawah yang menjadikan kegiatan menonton sebagai penyaluran tekanan hidup. Sejak awal berdiri identitas The Jakmania dibangun bukan berdasarkan suku, tetapi sebagai anak Jakarta atau anak Metropolitan. Orangorang dari berbagai suku yang tinggal di Jakarta dan orang-orang yang tinggal di sekitar Jakarta dapat mengidentifikasikan dirinya sebagai 
"anak Jakarta" dengan mendukung Persija. Meminjam istilah Guschwan (2011: 1991), "Fandom not as a trivial hobby but as a lifestyle."

Hasil deskriptif kuantitatif menggunakan metode rating scale, rata-rata variabel teknik kampanye public relations \#SaveGBK yang dilakukan menurut responden adalah tinggi. Pada variabel sikap responden rata-rata juga tinggi, hasil uji regresi berganda menunjukkan terdapat pengaruh signifikan dan kuat teknik kampanye terhadap sikap The Jakmania. Teknik kampanye tersebut dipandang melibatkan para anggota The Jakmania (dimensi partisipatif), pesan kampanye bergaung di dalam dan luar stadion (dimensi asosiasi), semakin menyatukan hati The Jakmania dengan Persija dan sesama suporter (dimensi integratif), menjadi kebanggaan, memberikan manfaat, dan menaikan citra positif The Jakmania (dimensi ganjaran), menggunakan hal-hal yang khas dan menarik (dimensi penataan patung es), peduli terhadap Persija dan sesama The Jakmania dan mencegah kerugian (dimensi empati), dan keikutsertaannya tidak memaksa (dimensi koersi). Penggunaan teknik kampanye ini mempengaruhi kognisi, afeksi, dan konasi dari responden. Mengacu pada Cottingham (2012: 168-185), "Fundamental to understanding fan behavior are the meaningful rituals and emotions experienced by fans". Mayoritas responden memiliki salah satu atau kedua orang tua berasal dari suku Betawi, identitas sosial kesukuan tidak berpengaruh terhadap sikap responden sehingga cocok dengan karakteristik majemuk penduduk Jabodetabek, juga menggambarkan kebhinekaan masyarakat Indonesia.

Sudut pandang Image Restoration Theory kampanye public relations \#SaveGBK dinilai sebagai correction action yang efektif mengajak The Jakmania menjaga SUGBK dan berperilaku lebih tertib karena menjadi panduan seharihari suporter dalam memberikan dukungannya terhadap Persija. Secara berkala pimpinan The Jakmania mengadakan briefing dengan para Korwil untuk membahas kegiatan-kegiatan yang dilakukan sekaligus memberikan pedoman untuk menjadi suporter yang tertib. Secara berjenjang hasil briefing itu disosialisasi para Korwil ke anggota masing-masing. Hal ini sejalan dengan penelitian Waruwu (2016: 25) bahwa kebutuhan koordinasi dalam organisasi muncul dari berbagai kewajiban yang harus diusahakan secara sinergis, dan kesadaran orang-orang yang melaksanakannya.

Pemberian sanksi pengurangan tiket bagi Korwil dan kehilangan hak menonton Persija di kelas ekonomi bagi para suporter menjadi senjata pimpinan The Jakmania dalam menegakkan aturan. Rata-rata suporter The Jakmania berasal dari kalangan anak muda menengah ke bawah, sehingga hanya dapat menjangkau tiket kelas ekonomi untuk menonton pertandingan Persija di stadion. Para supporter dengan label identitas 'anak Jakarta' menjadi kehilangan sarana aktualisasi diri sebagai penggemar sepak bola apabila mendapatkan sanksi pencabutan kartu anggota.

Hal ini berarti usaha menertibkan The Jakmania lebih efektif dari dalam melalui ancaman sanksi organisasi ketimbang hukuman dari luar, seperti ditahan polisi. Pada periode kepengurusan sebelumnya,tawuran antarsuporter dan kerusuhan yang berulang mengindikasikan suporter The Jakmania tidak menjadi jera. Perbaikan diri agar menjadi jera dalam organisasi melalui kampanye \#SaveGBK membuat The Jakmania menjadi lebih tertib. Perbaikan diri dalam membuat kohesivitas organisasi menjadi lebih kuat. Pendisiplinan untuk menjadi anggota The Jakmania sebagai corrective action, dalam kasus tertentu ke luar The Jakmania juga melakukan mortification, yakni penyesalan dan meminta maaf, seperti pada kasus perusakan salah satu sektor SUGBK pada Piala Presiden 2018.

Tren teknologi komunikasi membuat The Jakmania memanfaatkan media sosial untuk sosialisasi kebijakan organisasi dan pembentukan identitas sebagai "anak Jakarta". Komunitas virtual The Jakmania melalui Whatsapp Group 
dan Instagram menjadi landasan menggerakkan roda organisasi yang menjangkau hingga puluhan ribu anggotanya. Komunitas virtual tersedia kesempatan bagi pengguna berinteraksi dan membentuk hubungan (Chang \& Chuang, 2011). Mengacu tiga dimensi identitas sosial dari Feitosa et al. (2012: 531), yaitu kategorisasi, rasa memiliki, dan sikap positif yang dibangun The Jakmania tersalurkan melalui komunitas virtual. Hal itu sejalan dengan temuan Ortega (2019: 2118) di Liga Spanyol bahwa penggemar sepak bola menegaskan dan mengekspresikan identitas mereka melalui berbagai situs, jejaring sosial, aplikasi, dan pusat komunitas yang secara aktif terlibat dengan pengguna lain dalam produksi dan konsumsi konten budaya.

Hasil perhitungan kuantitatif didukung hasil wawancara dengan pimpinan suporter, penelitian ini menguatkan Image Restoration Theory bahwa strategi perbaikan citra berlangsung efektif dengan tindakan korektif dari dalam. Pada penelitian ini tindakan korektif dilakukan melalui penerapan teknik kampanye public relations yang mengandalkan komunikasi tatap muka langsung dan media sosial terhadap objek sikap, yaitu keberadaan SUGBK sebagai stadion kandang. Produk perilaku komunikatif, identitas sosial yang dibangun berdasarkan karakterik "anak Jakarta" yang bersifat lintas suku dan daerah.

The Jakmania tidak memiliki strategi pendekatan khusus dengan pihak media. Tanpa hubungan yang erat dengan pihak media upaya perbaikan organisasi dan pemulihan citra menjadi tidak terpublikasikan secara luas di masyarakat. Padahal sepak bola telah menjadi industri budaya massa yang menyebar secara global melalui industri media massa (Syahputra, 2016: 81). Hasil penelitian Putra (2011) juga menunjukkan, media memiliki pandangan sendiri atas kasus pro-kontra sepakbola sehingga memperteguh pandangan kaum konstruktivis bahwa berita adalah hasil konstruksi. Hal ini menyebabkan sebagian masyarakat masih memandang komunitas suporter seperti The Jakmania sebagai salah satu biang keributan dan kerusuhan sepakbola di Indonesia.

\section{Simpulan}

Kampanye public relations \#SaveGBK merupakan usaha partisipatif perbaikan dari dalam oleh The Jakmania sekaligus membangun citra. Dari hasil deskriptif kuantitatif rata-rata variabel Teknik Kampanye dan variabel Sikap dari responden sama-sama tinggi. Uji regresi berganda menunjukkan terdapat pengaruh signifikan teknik kampanye public relations terhadap sikap The Jakmania tanpa adanya pengaruh identitas sosial suku. Hasil penelitian kuantitatif menguatkan Image Restoration Theory bahwa strategi perbaikan citra melalui penerapan teknik kampanye public relations berlangsung efektif dengan tindakan korektif untuk penertiban ke dalam yang terbukti pada para anggota The Jakmania Depok.

Kompilasi temuan penelitian kuantitatif dan kualitatif menunjukkan, kampanye public relations \#SaveGBK berlangsung efektif karena terdapat pemberian sanksi organisasi dari pimpinan The Jakmania. Adanya keterkaitan kampanye public relations dengan sikap The Jakmania menunjukkan bahwa program perbaikan dari dalam organisasi dan kepemimpinan yang mampu mengelola jaringan komunikasi organisasi dapat menertibkan para anggotanya.

Karakteristik The Jakmania dalam segi tertentu menggambarkan miniatur masyarakat Indonesia. Berbeda dengan suporter klub lain semacam Bobotoh dan Aremania yang memiliki unsur lokalitas dan etnisitas, identitas sosial The Jakmania tidak hanya cocok dengan karakteristik majemuk penduduk Jabodetabek, juga sesuai dengan kebhinekaan masyarakat Indonesia. Dengan rata-rata anggota The Jakmania berasal dari kalangan menengah ke bawah, kegiatan menonton sepakbola menjadi sarana penyaluran tekanan hidup yang mampu mereka jangkau. Substansi penelitian ini memberi masukan bagi kebijakan strategi membangun fanatisme positif suporter sepakbola Indonesia yang bersifat lintas suku dan daerah melalui tindakan korektif terprogram dari internal organisasi. 
Substansi penelitian ini berupa usulan kebijakan pada The Jakmania perlu membangun strategi pendekatan dengan media melalui pembentukan tim khusus media relations agar upaya perbaikan organisasi dapat diketahui masyarakat luas dan citra positifnya meningkat. Tim media relations itu mengelola program-program siaran pers, konferensi pers, wawancara media, dan even khusus.

\section{Daftar Pustaka}

Albarracin, D., Johnson, B.T., Zanna, M. P. (2005). The Handbook of Attitudes (2nd ed.). New York: Psychology Press. Azwar, S. (2016). Sikap Manusia: Teori dan Pengukurannya. Yogyakarta:PustakaPelajar. Benoit, W. L. (1997). Image repair discourse and crisis communication. Public Relations Review, 23(2), 177-186. https://doi. org/10.1016/S0363-8111(97)90023-0

Bowen, P., Rose, R., \& Pilkington, A. (2017). Mixed Methods-Theory And Practice. Sequential, Explanatory Approach. International Journal of Quantitative and Qualitative Research Methods, 5(2), 10-27. Chang, H.H. \& Chuang, S. (2011). Social capital and individual motivations on knowledge sharing: Participants involvement as a moderator. Information \& Management, 48(1), 9-18. https:// doi.org/10.1016/j.im.2010.11.001

Coombs, W.T., \& Holladay, S. J. (2008). Comparing Apology to Equivalent Crisis Response Strategies: Clarifying Apology's Role and Value in Crisis Communication. Public Relations Review, 34(3), 252-257. Diakses dari https://www.sciencedirect.com/ science/article/abs/pii/S0363811108000593

Cottingham, M. D. (2012). Interaction Ritual Theory and Sports Fans: Emotion, Symbols, and Solidarity. Sociology of Sport Journal, 29(2), 168-185. https://doi.org/10.1123/ssj.29.2.168 Doewes, R.I. \& Riyadi, S. (2016). The
Social Identity of Football Supporters In Providing Sportive Support To Arema Player (A Phenomenology Study to Supporter of Aremania in Malang). The 1st International Conference on Teacher Training and Education (ICTTE) FKIP UNS 2015, 718-725. Diakses dari https:// digilib.uns.ac.id/dokumen/detail/48399/ The-Social-Identity-of-Football-Supportersin-Providing-Sportive-Support-toArema-player-A-Phenomenology-Studyto-Supporter-of-Aremania-in-Malang Feitosa, J., Salas, E., \& Salazar, M. R. (2012). Social Identity: Clarifying Its Dimensions Across Cultures. Psychological Topics, 21(3), 527-548. Diakses dari https:// psycnet.apa.org/record/2013-03108-008 Goodall, C. E. (2011). An Overview of Implicit Measures of Attitudes: Methods, Mechanisms, Strengths, and Limitations. Communication Methods and Measures, 5(3), 203-222. https:// doi.org/10.1080/19312458.2011.596992 Guan, M., \& So, J. (2016). Influence of Social Identity on Self-Efficacy Beliefs Through Perceived Social Support: A Social Identity Theory Perspective. Communication Studies, 67(5), 588-604. https://doi. org/10.1080/10510974.2016.1239645 Guschwan, M. (2011). Fans, Romans, Countrymen: Soccer Fandom and Civic Identity in Contemporary Rome. International Journal of Communication, 5(1), 1990-2013. Diakses dari https:// ijoc.org/index.php/ijoc/article/view/869 Hadi, A. (2017). "Bobotoh Persib" dan Konstruksi Identitas di Era Digital. Jurnal Masyarakat Dan Budaya, 19(1), 131-151. https://doi.org/10.14203/jmb.v19i1.434 Hogg, M. A. (2018). Self-Uncertainty, Leadership Preference, and Communication of Social Identity. Atlantic Journal of Communication, 26(2), 111-121. https:// doi.org/10.1080/15456870.2018.1432619 
Huiberts, E. (2016). Building Bridges, Filling Gaps: Toward an Integrative Interdisciplinary and Mixed-Methods Approach for Future Audience Research in Relation To The Mediation Of Distant Suffering. International Journal of Communication, 10, 4324-4344. Diakses dari https://ijoc. org/index.php/ijoc/article/view/4675 Ibrahim, L. A. N. (2017). Managing the Reputation of the Federation Internationale de Football Association (FIFA): The Case of the Corruption Crisis. Public Relations Journal, 11(2), 1-18. https:// prjournal.instituteforpr.org/wpcontent/uploads/FIFA-Corruption.pdf

Koerber, D., \& Zabara, N. (2017). Preventing Damage: The psychology of Crisis Communication Buffers in Organized Sports. Public Relations Review, 43, 193-200. https://doi. org/10.1016/j.pubrev.2016.12.002 Kriyantono, R. (2014). Teknik Praktis Riset Komunikasi. Jakarta: Kencana Prenadamedia Group.

Ortega, V. R. (2019). Online Soccer Fandom: From Social Networking To Gaming. Sport in Society, 22(12), 2104-2121. https:// doi.org/10.1080/17430437.2019.1566320

Porat, A. B. (2010). Football Fandom: A Bounded Identification. Soccer and Society, 11(3), 277-290. https://doi. org/10.1080/14660971003619594
Prasetya, M. H. (2016). Suporter Rusuh, Persija Jakarta Dapat Sanksi Tambahan. tribunnews. com. Diambil dari http://www.tribunnews. com/superskor/2016/07/03/suporter-rusuhpersija-jakarta-dapat-sanksi-tambahan Putra, A. M. (2011). Sepak Bola Indonesia dalam Bingkai Pemberitaan Media. Jurnal Ilmu Komunikasi, 9(3), 312-323. Diakses dari http://www.jurnal.upnyk.ac.id/ index.php/komunikasi/article/view/3439

Rice, R. E., Evans, S. K., Pearce, K. E., Sivunen, A., Vitak, J., \& Treem, J. W. (2017). Organizational Media Affordances: Operationalization and Associations with Media Use. Journal of Communication, 67, 106-130. https://doi.org/10.1111/jcom.12273 Ruslan, R. (2013). Kampanye Public Relations. Jakarta: PT. Raja Grafindo Persada. Syahputra, I. (2016). Religiusitas Sepak Bola dalam Rezim Media: Perspektif Fans Sepak Bola Indonesia. Jurnal Ilmu Komunikasi, 14(2), 80-91. Diakses dari http://jurnal.upnyk.ac.id/index. $\mathrm{php/komunikasi/article/view/2122}$ Waruwu, K. (2016). Strategi Keberhasilan Organisasi Berdasarkan Program Organizational Development and Change. Jurnal Ilmu Komunikasi, 14(1), 22-29. Diakses dari http://jurnal.upnyk.ac.id/ index.php/komunikasi/article/view/2116 